\title{
Basic differences in the health profile between seafarers from the Philippines and Denmark
}

\author{
Henrik Lyngbeck Hansen ${ }^{1}$, Glennda Canlas $^{2}$ \\ ${ }^{1}$ Greenland Health Authorities, Nuuk, Greenland \\ ${ }^{2}$ Halcyon Marine Healthcare Systems, Manila, Philippines
}

\begin{abstract}
Background: Seafarers in international trade are today recruited world-wide based on qualifications and costs. Health is another aspect. In this study, two cohorts of seafarers from the Philippines and Denmark undergoing pre-employment health examinations were compared. The purpose is to investigate differences in the outcome of the examinations and compare basic parameters.

Materials and methods: Two cohorts of equal number of seafarers from the Philippines and Denmark were established. A total of 9,654 consecutive health examinations at a large clinic in the Philippines were compared with a group with the same size examined in a number of clinics in Denmark. The Filipino seafarers were screened according to different company standards whereas the Danish seafarers were examined according to statutory standards.

Results: The age structure was different. Only $18 \%$ of seafarers from the Philippines were 45 years of age or above whereas almost $43 \%$ of the Danish seafarers were in this age category. Obesity was frequent in both cohorts although depending on the standard used as reference. Extreme obesity (body mass index, above 35) was 10 times more frequent among the Danish seafarers. A total of $4.4 \%$ of the Filipino seafarers were declared unfit whereas only $0.5 \%$ were found unfit among the Danish seafarers. Among the latter, $5.2 \%$ were found fit with limitations, which is a category not used in the Philippines.

Conclusions: The two groups are inhomogeneous and the health examinations the seafarers underwent differ. Comparisons should be done with caution. The difference in the age distribution of the two groups of seafarers is important factor due to the strong impact of age on health. Obesity was of major concern in both groups, although there were more with severe overweight and especially with extreme overweight among the Danish seafarers. Smoking frequency seems to be on the same level.
\end{abstract}

(Int Marit Health 2019; 70, 4: 210-215)

Key words: maritime medicine, pre-employment health examinations

\section{INTRODUCTION}

The maritime business is becoming increasingly globalised. Shipowners have their ships flagged where business is easiest. Crews are recruited internationally. Well-educated crews are found in many places round the world and nationality plays a minor role in many shipping companies [1]. Selection of crews is increasingly based on the total cost. Crew expenses depend on salaries and employment conditions. International salaries for highly qualified seafarers are becoming closer to each other, but considerable better employment conditions generally makes seafarers from Western countries more costly.

Health is an upcoming cost of seafarers. Health expenses in foreign ports, repatriation costs and claims have increased focus on this issue in some parts of the world. The insurance companies, in the maritime world named $P$ \& I Clubs, have responded to this and introduced programmes to avoid employing seafarers who potentially may be an economic burden [2]. Despite worldwide use of pre-employment health examinations [3] repatriation 
of seafarers is common and the economic costs are high $[4,5]$.

This study is a comparison of the basic results of pre-employment health examinations in one large clinic in the Philippines and in Denmark. The purpose is to compare the outcome of the examinations and compare basic parameters, including age structure, overweight and smoking habits, and identify weaknesses and strengths in the two groups of seafarers.

\section{MATERIALS AND METHODS}

A total of 9,654 consecutive health examinations from the large Halcyon Marine Healthcare Systems (Manila) a clinic serving a large number of manning agencies - were drawn from the clinics database and anonymised before analysed. The examinations were done in the period from 5 January 2015 to 29 December 2015. The health examinations were performed according to the standards of a number of manning agencies and shipping companies. The seafarers included were all examined for the first time in the Halcyon Marine Healthcare Systems. Their maritime history was not available. The examined seafarers were to work in the international maritime industry.

A cohort of seafarers of similar size examined in Denmark was afterwards withdrawn from the Danish register on statutory health examinations performed in clinics in Denmark [6]. The examination is based on international guidelines [7]. The retrieval started with the newest recorded examination in 2015 and then going backwards until a total of 9,654 examinations were included. The Danish participants were residents in Denmark. The statutory Danish health examination only gives access to work on Danish registered ships. In both cohorts, a seafarer could only be included once.

As the system functions different in the two countries, there are also different outcomes of the examinations. In Denmark, seafarers may be "fit with limitations", which means they get permission to work in e.g. a limited geographical area, in certain positions or reduced length of the validity of the certificate. In the Philippines, the result is either you are fit or unfit. In some cases, the recorded result of the examination is
"Expired". This means that the process of the health examination was not finished within a certain time limit. Similar situations may occasionally occur in Denmark, but it is not recorded.

Body mass index (BMI) is used in this study to compare overweight. For Filipino seafarers, two different standards are used, namely an international standard and an Asian standard. The international standard defines obesity as a condition with a BMI of 25 or above [8]. The Asian standard defines BMI of 23 and above as obesity [9]. For Danish seafarers, only the international standard was applied. The international standard defines severe overweight when BMI reaches 30 or above. The Asian standard defines severe overweight when BMI is 28 or above.

Information about smoking only exists in the Philippine data. A smoker was defined as a person who defined himself/herself as a smoker.

\section{RESULTS}

\section{RESULTS OF THE EXAMINATION}

The overall results of the health examinations are presented in Table 1.

The age distribution of all seafarers in the two cohorts is presented in Table 2.

The two groups of seafarers are in some aspects quite different in composition. There are many more working in catering and hotel jobs among the Filipino seafarers. To make the age distribution more comparable, the age distribution of seafarers working in traditional maritime positions on deck and in engine room is shown in Table 3.

Chief engineers examined in Denmark had a mean age of 52.0 years $(n=329)$ and the same category examined in the Philippines $(n=183$ ) had a mean age of 49.6 years.

Captains examined in Denmark had a mean age of 54.2 years $(n=1045)$ and the same category examined in the Philippines $(n=42)$ had a mean age of 48.4 years.

\section{OVERWEIGHT}

In Figure 1, the percentage of seafarers with overweight is shown. The proportion of seafarers with a BMI exceeding

Table 1. The final results of the health examinations in the Philippines and in Denmark

\begin{tabular}{|c|c|c|c|c|}
\hline \multirow[t]{2}{*}{ Result of examination } & \multicolumn{2}{|l|}{ Filipino } & \multicolumn{2}{|l|}{ Danish } \\
\hline & Number & Percentage & Number & Percentage \\
\hline Fit for duty without limitations & 8987 & $93.1 \%$ & 9104 & 94.3 \\
\hline Fit with limitations & 0 & $0 \%$ & 502 & $5.2 \%$ \\
\hline Unfit & 428 & $4.4 \%$ & 48 & $0.5 \%$ \\
\hline Expired & 239 & $2.5 \%$ & 0 & $0 \%$ \\
\hline Total & 9654 & $100.0 \%$ & 9654 & $100.0 \%$ \\
\hline
\end{tabular}


Table 2. Basic age distribution in the two study populations

\begin{tabular}{|c|c|c|c|c|c|c|c|c|}
\hline \multirow[t]{3}{*}{ Age group [years] } & \multicolumn{4}{|c|}{ Female seafarers } & \multicolumn{4}{|c|}{ Male seafarers } \\
\hline & \multicolumn{2}{|l|}{ Filipino } & \multicolumn{2}{|l|}{ Danish } & \multicolumn{2}{|l|}{ Filipino } & \multicolumn{2}{|l|}{ Danish } \\
\hline & Number & Percentage & Number & Percentage & Number & Percentage & Number & Percentage \\
\hline Below 18 & 0 & $0.0 \%$ & 24 & $2.1 \%$ & 4 & $0.0 \%$ & 135 & $1.6 \%$ \\
\hline $18-24$ & 116 & $23.9 \%$ & 343 & $29.9 \%$ & 1574 & $17.2 \%$ & 1265 & $14.9 \%$ \\
\hline $25-34$ & 267 & $54.9 \%$ & 275 & $23.9 \%$ & 3291 & $35.9 \%$ & 1750 & $20.6 \%$ \\
\hline $35-44$ & 88 & $18.1 \%$ & 168 & $14.6 \%$ & 2645 & $28.9 \%$ & 1730 & $20.3 \%$ \\
\hline $45-54$ & 13 & $2.7 \%$ & 217 & $18.9 \%$ & 1312 & $14.3 \%$ & 1972 & $23.2 \%$ \\
\hline $55-64$ & 2 & $0.4 \%$ & 116 & $10.1 \%$ & 338 & $3.7 \%$ & 1316 & $15.5 \%$ \\
\hline $65+$ & 0 & $0.0 \%$ & 6 & $0.5 \%$ & 4 & $0.0 \%$ & 337 & $4.0 \%$ \\
\hline Total & 486 & $100.0 \%$ & 1.149 & $100.0 \%$ & 9.168 & $100.0 \%$ & 8.505 & $100.0 \%$ \\
\hline
\end{tabular}

Table 3. Age distribution of male seafarers in traditional maritime positions on deck and the engine room

\begin{tabular}{|c|c|c|c|c|}
\hline \multirow{3}{*}{$\begin{array}{l}\text { Age group } \\
\text { [years] }\end{array}$} & \multicolumn{4}{|c|}{ Male seafarers, deck and engine } \\
\hline & \multicolumn{2}{|l|}{ Filipino } & \multicolumn{2}{|l|}{ Danish } \\
\hline & Number & Percentage & Number & Percentage \\
\hline Below 18 & 4 & $0.1 \%$ & 135 & $2.1 \%$ \\
\hline $18-24$ & 1140 & $17.7 \%$ & 1128 & $14.4 \%$ \\
\hline $25-34$ & 2078 & $32.3 \%$ & 1589 & $20.3 \%$ \\
\hline $35-44$ & 1921 & $29.8 \%$ & 1569 & $24.4 \%$ \\
\hline $45-54$ & 1004 & $15.6 \%$ & 1832 & $28.4 \%$ \\
\hline $55-64$ & 294 & $4.6 \%$ & 1236 & $15.8 \%$ \\
\hline $65+$ & 2 & $0.0 \%$ & 329 & $4.2 \%$ \\
\hline Total & 6.443 & $100.0 \%$ & 7.818 & $100.0 \%$ \\
\hline
\end{tabular}

the definitions of overweight was compared in each age group. The results from the two cohorts have been compared for each age group using chi-square statistic (Social Science Statistics). For all age groups except seafarers of 65 years of age and above the results are statistically significant ( $p$-value < 0.05).

The analysis of severe overweight is presented in Figure 2. Among the 941 Filipino seafarers with severe overweight (international standard), 28 were female. The results from the two cohorts have been compared for each age group using chi-square statistic. For all age groups except seafarers of 65 years of age and above the results are statistically significant ( $p$-value < 0.00001). A total of $49(0.5 \%$, 3 females and 46 males) of the Filipino seafarers were extremely obese (BMI 35 and above). In comparison, there were

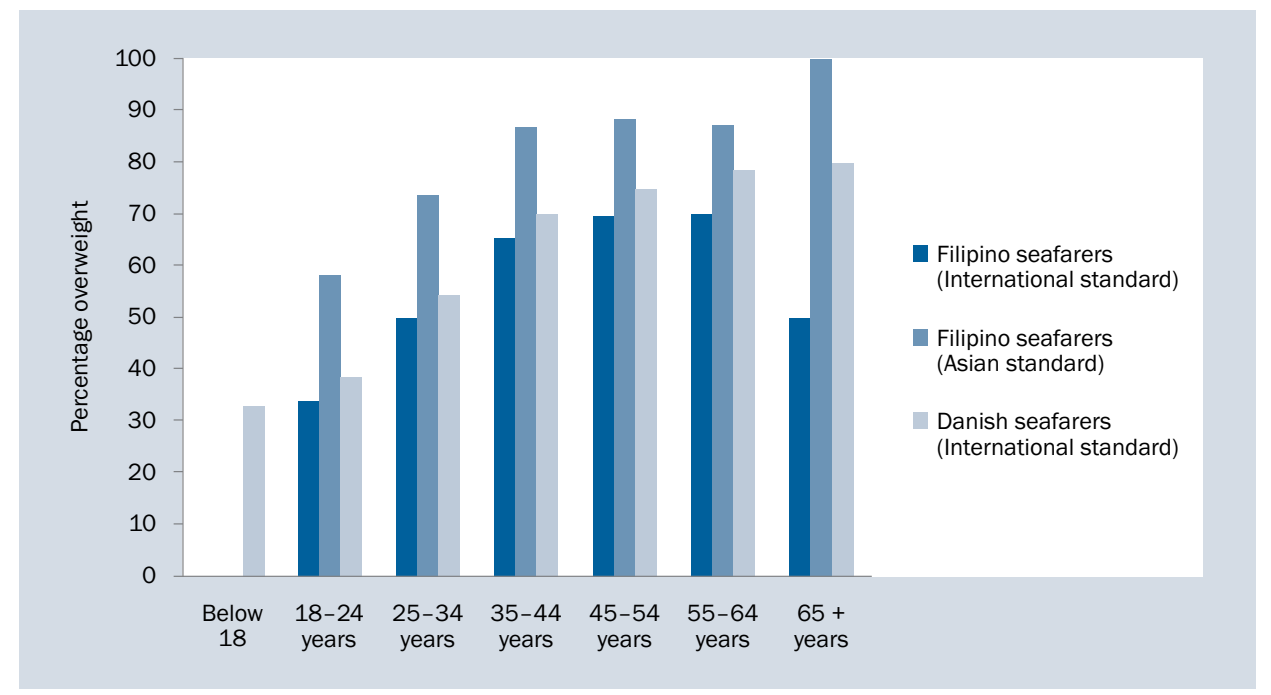

Figure 1. Comparison of the percentage of overweight in different age-groups of seafarers (both sexes) 


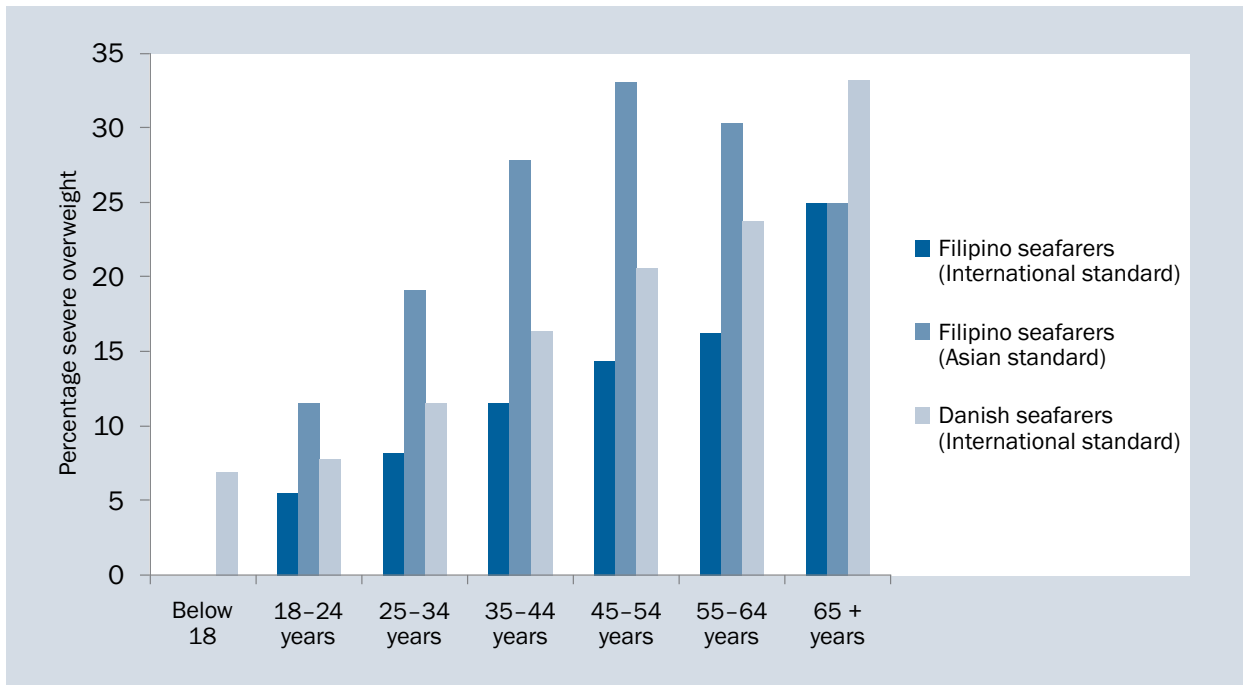

Figure 2. Comparison of the percentage of severe overweight in different age-groups of seafarers (both sexes)

600 Danish seafarers $(6.2 \%, 72$ females and 528 males) with extreme obesity.

\section{SMOKING}

A total of $14.0 \%$ of the female seafarers and $32.0 \%$ of the male seafarers were recorded as smokers. Both among females and males, the highest rate were found in the age group 25-34 years. The percentage was $16.1 \%$ and $34.5 \%$, respectively. For both genders, the lowest rate were seen among 18-24 years old seafarers, were the figures were $10.3 \%$ and $26.9 \%$, respectively.

Among the male non-smokers, 55.2\% were overweight whereas $58.5 \%$ of the smokers were overweight. Male seafarers with severe overweight had a smoking frequency of $10.8 \%$ whereas $9.6 \%$ of the non-smokers were overweight.

Smoking rates between deck and engine officers and deck and engine ratings were compared and the results are shown in Table 4. The difference between officers and rating is significant at $p<0.01$ (chi-square statistic).

\section{DIABETES}

In both countries, all seafarers are examined for the presence of diabetes. In the Philippines fasting blood glucose is measured and seafarers with elevated levels have to undergo an oral glucose tolerance test. At the initial screening, 295 out of 6592 (4.5\%) had blood glucose levels of $7.0 \mathrm{mmol} / \mathrm{L}$ or above. In the age group 18-24 years, $0.8 \%$ blood glucose levels were $7.0 \mathrm{mmol} / \mathrm{L}$ or above, increasing to $16.5 \%$ in the age group $55-64$ years.

In the Danish dataset, 262 (2.7\%) of those who were declared fit were recorded as having diabetes. The type of diabetes was only recorded in 111 cases. Among these 111 seafarers, ten had type 1 diabetes and the remaining 101 seafarers had type 2 .
Table 4. Smoking frequency among Filipino officers and ratings in deck and engine departments

\begin{tabular}{lccl}
\hline $\begin{array}{l}\text { Smoking, Filipino } \\
\text { seafarers }\end{array}$ & Non-smoker & Smoker & $\begin{array}{l}\text { Percentage } \\
\text { smokers }\end{array}$ \\
\hline $\begin{array}{l}\text { Officers, deck and } \\
\text { engine }\end{array}$ & 1309 & 458 & $25.9 \%$ \\
$\begin{array}{l}\text { Ratings, deck and } \\
\text { engine }\end{array}$ & 3158 & 1560 & $33.1 \%$ \\
\begin{tabular}{l} 
Total \\
\hline
\end{tabular} & 4467 & 2018 & $31.1 \%$ \\
\hline
\end{tabular}

\section{DISCUSSION}

The present study is a comparison of basic data of two cohorts of seafarers from the Philippines and Denmark. No such studies seem to have been made earlier. Both represent seafaring countries of major importance and the crews are to some extent competing for the same positions in a globalised maritime business.

The Danish cohort may be seen as representative of the seafaring population in Denmark, but there are likely to be selection bias in the Filipino cohort. The seafarers in the two countries are subject to different regulations and the two groups differ in a number of ways. The Filipino seafarers have to meet a number of different standards and have been through a strong selection process in their career. A strong "healthy worker effect" can be expected [10]. The Philippine data only include health examinations performed in one clinic, but due to the fact that they are only seafarers examined for the first time in the clinic, it is likely that they are comparable to other Philippine seafarers. Few Danish seafarers are declared unfit and the Danish seafarers are therefore probably not exposed to the same selection pressure. In Denmark, there may although be a considerable self-selection due to health problems due to 
access to social benefits [11]. As the Danish cohort includes all seafarers examined in the country in the selected period, they are per definition representative of Danish seafarers.

The results of the health examinations vary considerably in the two cohorts although the results are not fully comparable. Among the Filipino seafarers, $2.3 \%$ never fulfilled the examination process, whereas all recorded Danish cases came to a conclusion. Danish examinations not completed may in some cases never been recorded.

The percentage of seafarers declared unfit was higher in the Philippines. The purpose of the examinations is different in the two countries, which is reflected in the results. The differences between the two groups cannot be interpreted as differences in the health condition in the two groups but more likely reflect the differences in two very different systems. The Filipino system is in principle an insurance-based system, where the employers want to reduce costs by avoiding potentially unhealthy seafarers [2]. There are variations in standards to be met from different manning agencies and shipowners. Seafarers from the Philippines are to work world-wide on long contracts. They are therefore to meet higher standards compared to other settings, e.g. Denmark, were limitations in field of work on board, area of trade and validity of the health certificate may be acceptable conditions. The Danish health examinations are based on a statutory based scheme with a limited insurance aspect and only fulfilling the minimum standards defined by International Labour Organisation [5]. The health insurance of the seafarers is paid by the Danish government although the shipowners contribute. The shipowner may have a more limited interest in the health status of the employed compared to most other countries, where the shipowners are to pay the full costs.

The age distribution between the two groups of seafarers is remarkable. The overall difference in mean age is more than 5 years. The age distribution is influenced by a large proportion of seafarers employed in catering and hotel business. When looking at male seafarers working in the deck and engine compartments, the differences are even more pronounced and these seafarers are competing for the same positions. There are more than three times as many Danish seafarers in the age group 55-64 years. Among captains and chief engineers, age differences are less, and the differences thus to some extent are likely to reflect differences in position the two nationalities in the maritime hierarchy. As burden of disease increases steeply with age [12], the significant differences in age structure is from an economic point of view a big advantage to the Philippine seafarers. Health expenditures can be expected to be considerable lower making this group more competitive.

Seafarers of both nationalities showed high frequency of overweight although the Danish seafarers are statistically significant most overweight and thus have a higher risk of obesity related morbidity and mortality. The differences were more pronounced when looking at severe overweight. The Danish seafarers are known to have a considerable higher level of overweight compared to the rest of the population in Denmark [13]. The metabolic syndrome has been shown to be frequent among Danish seafarers. In a survey, one in four had the syndrome [14].

About one third of the male seafarers from the Philippines were smokers. In a recent Danish survey, $30.6 \%$ were current smokers [15]. There is thus no evidence for marked differences for this risk factor. Diabetes and pre-diabetic conditions were common in both nationalities but the figures are not directly comparable. A steep increase in abnormal fasting blood glucose with age was seen among the Filipino seafarers. Almost 3\% of the fit Danish seafarers had a diagnosis of diabetes. According to international standards, type 1 diabetes should not be permitted to work at sea [7], but may be accepted according to Danish standards. The total number is likely to be low, and self-selection is likely to be important, as diabetes is more common in the Danish population than among the seafarers.

\section{CONCLUSIONS}

The present study show a major difference in the age distribution of the two groups, which may be the most important factor when evaluating differences in health between the two groups of international seafarers. Obesity was of major concern in both groups, although there were more people with severe overweight and especially with extreme overweight among the Danish seafarers. Smoking seems to be on the same level. The more strict health standards to be met in the Philippines are likely to create a more pronounced healthy worker effect. In conclusion, the risk of lifestyle-related disease is likely to be lower among the Filipino seafarers.

\section{REFERENCES}

1. Guillot-Wright $\mathrm{S}$. The changing economic structure of the maritime industry and its adverse effects on seafarers' health care rights. Int Marit Health. 2017; 68(2): 77-82, doi: 10.5603/IMH.2017.0015, indexed in Pubmed: 28660609.

2. P\&I Clubs. In: Textbook of Maritime Medicine, Chapter 6.5. http:// textbook.ncmm.no/.

3. Seidenstücker K, Neidhardt S, Schepers B. Pre-employment medical examinations - what is the issue? Int Marit Health. 2017; 68(3): 174-175, doi: 10.5603/IMH.2017.0031, indexed in Pubmed: 28952664.

4. Abaya AR, Roldan S, Ongchangco JC, et al. Repatriation rates in Filipino seafarers: a five-year study of 6,759 cases. Int Marit Health. 2015; 66(4): 189-195, doi: 10.5603/IMH.2015.0038, indexed in Pubmed: 26726888.

5. Faurby MD, Jensen OC, Hjarnoe L, et al. The costs of repatriating an ill seafarer: a micro-costing approach. Health Econ Rev. 2017; 
7(1): 46, doi: 10.1186/s13561-017-0184-0, indexed in Pubmed: 29209881.

6. Danish Maritime Authorities. Medical examinations in Denmark. https://www.dma.dk/SoefarendeBemanding/LaegeHelbred/ Laegeundersoegelse/Sider/LaegeundersoegelseDanmark.aspx.

7. Guidelines on the medical examinations of seafarers. https:// www.ilo.org/sector/Resources/codes-of-practice-and-guidelines/ WCMS_174794/lang-en/index.htm.

8. Weisell R. Body mass index as an indicator of obesity. Asia Pacific J Clini Nutrition. 2002; 11(s8): S681-S684, doi: 10.1046/j.14406047.11.s8.5.x.

9. WHO expert consultation. Appropriate body-mass index for Asian populations and its implications for policy and intervention strategies. Lancet. 2004; 363(9403): 157-163, doi: 10.1016/s01406736(03)15268-3.

10. Chowdhury R, Shah D, Payal AR. Healthy Worker Effect Phenomenon: Revisited with Emphasis on Statistical Methods - A Review. Indian J Occup Environ Med. 2017; 21(1): 2-8, doi: 10.4103/ijoem.IJOEM_53_16, indexed in Pubmed: 29391741.
11. Pedersen J, Bjorner JB. Worklife expectancy in a cohort of Danish employees aged 55-65 years - comparing a multi-state Cox proportional hazard approach with conventional multi-state life tables. BMC Public Health. 2017; 17(1): 879, doi: 10.1186/s12889-017-4890-7, indexed in Pubmed: 29141598.

12. de Meijer C, Wouterse B, Polder J, et al. The effect of population aging on health expenditure growth: a critical review. Eur J Ageing. 2013; 10(4): 353-361, doi: 10.1007/s10433-013-0280-x, indexed in Pubmed: 28804308.

13. Hansen HL, Hjarnoe L, Jepsen JR. Obesity continues to be a major health risk for Danish seafarers and fishermen. Int Marit Health. 2011; 62(2): 98-103, indexed in Pubmed: 21910112.

14. Jepsen JR, Rasmussen HB. The metabolic syndrome among Danish seafarers: a follow-up study. Int Marit Health. 2016; 67(3): 129-136, doi: 10.5603/IMH.2016.0025, indexed in Pubmed: 27681211.

15. Møller Pedersen SF, Jepsen JR. The metabolic syndrome among Danish seafarers. Int Marit Health. 2013; 64(4): 183-190, doi: 10.5603/imh.2013.0002, indexed in Pubmed: 24408138. 